\title{
COMMISSION 16: PHYSICAL STUDY OF PLANETS AND SATELLITES
}

\author{
(ETUDE PHYSIQUE DES PLANETES ET DES SATELLITES)
}

\author{
PRESIDENT: Dale Cruikshank \\ VICE-PRESIDENT: Régis Courtin \\ ORGANIZING COMMITTEe: M. Belton, C. Blanco, A. Coradini, C. de Bergh, \\ L. Ksanfomality, M. McGrath, K. Noll, T. Owen, J. Spencer \& V. Tejfel
}

\section{Introduction}

This report includes some of the major achievements in studies of planets and satellites that have been accomplished during the years 1999-2002.

\section{Mercury}

\section{Ann L. Sprague}

Ground-based observations of Mercury continue to add to our knowledge of the character and composition of Mercury's surface, exosphere, and putative volatiles stored in high latitude, perpetually shadowed craters. Improved capability of imaging facilities, infrared spectrographs, detectors and image processing has permitted measurements at previously inaccessible wavelengths, higher-than-ever spatial resolutions, and with more sensitivity to faint emissions.

Additions and improvements to the McMath Pierce Solar telescope on Kitt Peak have permitted the imaging of the newly discovered sodium ( $\mathrm{Na}$ ) tail streaming anti-sunward from Mercury during periods of high radiation pressure (Potter et al. 2002), and visible at times of appropriate orbital geometry. The Na tail, predicted by modeling, was found to contain about 1-10\% of the total Na inventory in the thin exosphere. Atmospheric calcium was discovered by Bida et al. (2001) using the High Resolution Spectrograph (HIRES) at the Keck I telescope. Calcium was discovered off the southern hemisphere of the planet, and the doppler shift indicates a rather energetic source mechanism, such as charged particle sputtering from Mercury's surface.

Rapid imaging at visible wavelengths with the $1.5 \mathrm{~m}$ telescope at Mt. Wilson Observatory captured many "perfect seeing" images of the "unknown side" of Mercury (Mendillo et al. 2001). Using an automated co-alignment procedure, they constructed a composite image of Mercury from longitudes $270^{\circ}-330^{\circ}$ showing albedo features that resemble the bright, fresh craters, and darker maria of the Moon. Other images, obtained with the Solar Vacuum Telescope at La Palma, also show contrasting light and dark regions on the previously unimaged side of Mercury that resemble light and dark regions on the lunar surface in images of similar spatial resolution (Warell \& Limaye 2001). Ongoing observations with a CCD at the Crimean Observatory (Ksanfomality 2002) are also producing images of Mercury's surface in unprecedented detail. Mallama et al. (2002) determined the photometric phase function from $2^{\circ}$ to $170^{\circ}$ using the SOHO satellite.

The Aricebo (Puerto Rico) upgraded radar facility has permitted imaging of unprecedented detail on Mercury's surface (Harmon et al. 2001). Craters as small as 1.5-3 km have now been imaged at $S$ band $(12.6 \mathrm{~cm})$ and all of the northern high latitudes have been thoroughly mapped. The observations confirm the presence of the original polar features 
and reveal many additional regions having the same strong reflectivity as those found earlier and attributed to ice deposits. Models of the stability of volatiles and semi-volatiles at high latitudes on Mercury's surface show that water ice can be retained if it lies in perpetually shadowed regions and is covered with a thin layer of regolith. Alternative sources for the strong radar backscatter signals could be materials that are very transparent at radar wavelengths, such as sulfur or very cold glassy silicates.

Multicolor photometric and spectral observations of the "unknown" side of Mercury performed with the Swedish Vacuum Solar Telescope during 1997 and 1998 (Warell 2002) demonstrate that there is no evidence in Mercury's reflectance spectrum for any absorption by $\mathrm{FeO}$; previous results on the same spectral band were ambiguous. The absence of the $\mathrm{FeO}$ band indicates that any surface basalts or other common silicates must be highly reduced. Either all the $\mathrm{Fe}$ is in the core, or it has been converted to Fe metal by meteoritic comminution. In addition, the surface is more backscattering than the Moon over the visible and near-IR wavelengths, supporting the absence of $\mathrm{FeO}$ or $\mathrm{TiO}$.

Mid-infrared spectral observations made at the NASA Infrared Telescope Facility reported by Sprague et al. (2002) show spectral features indicative of soils ranging from $\sim 47-62 \% \mathrm{SiO}_{2}$, which in petrologic terms fall between "intermediate" and "basic". In addition, a strong spectral feature centered at $5 \mu \mathrm{m}$ may indicate the presence of clinopyroxenes. Such pyroxene as may be present must be high in $\mathrm{Ca}, \mathrm{Mg}$, or both to be consistent with the absence of FeO. Cooper et al. (2001) studied the wavelength variation of the central minimum in a special mid-infrared spectral band of silicates called the transparency feature. Variability of the central wavelength of this feature across Mercury is evidence of compositional heterogeneity on the planet, consistent with other mid-infrared observations at other wavelengths.

Apart from its orbital characteristics, nearly every other issue concerning Mercury and its physical properties is unresolved. The cursory reconnaissance made by Mariner 10 in the mid 1970s provided incomplete knowledge of the surface, atmosphere, and magnetic properties, with only about $45 \%$ of the surface imaged and about 30 minutes of measurements of particles and fields. The ground-based observations described above, as good as they are, have raised many more questions about the composition of the surface and the putative volatiles at high latitude than they have answered. More ground-based studies are required, and spacecraft reconnaissance is essential to provide us with a comprehensive picture of Mercury's origins and its place in the larger picture of the origin and development of terrestrial planets.

Many of the outstanding questions regarding Mercury will be addressed by the MErcury Surface, Space ENvironment, GEochemistry, and Ranging (MESSENGER) spacecraft mission. MESSENGER is a NASA Discovery mission expected to be launched in 2004. Solomon et al. (2002) give a detailed account of the major scientific issues to be addressed during cruise to, and orbit around, the planet. Measurements made with the suite of seven instruments will address such fundamental issues as the geological history, processes of formation that led to the high metal/silicate proportions, the magnetic field, structure and state of the core, identification of the radar-reflective materials at the poles, and the sources and sinks of volatile species on the planet. With the current launch schedule, MESSENGER will enter an orbit around Mercury in April 2009 (Gold et al. 2001).

The European Space Agency (ESA) also has planned a cornerstone mission to Mercury called Bepi Colombo. Currently in its design stage, the mission may include both an orbiter and landed components, with an anticipated launch early in the next decade.

\section{The Moon}

\section{G. Jeffrey Taylor}

Interdisciplinary research in lunar science has blossomed during the past three years, leading to fresh insights into the nature of the Moon. Impressive global data sets were acquired by the Clementine and Lunar Prospector missions in the 1990s, and they have been used widely 
during the past three years. Lunar research was also stimulated and focused by an initiative called New Views of the Moon Enabled by Combined Remotely Sensed and Lunar Sample Data Sets. This initiative was started in 1998 by the Curation and Analysis Planning Team for Extraterrestrial Materials (a NASA committee managed by the Lunar and Planetary Institute). Its goal was to synthesize diverse data sets to increase our understanding of the Moon. The initiative led to improved understanding of the Moon, but perhaps more importantly, it showed how to integrate all information about a planetary body through interdisciplinary research.

Studies have also benefited from a new source of lunar material. The first lunar meteorite was identified some 20 years ago, but their number has doubled in the past three years thanks to extensive dry desert searches. The number of known lunites as of 2002 is 36 separate rocks, but many are paired, so the number of separate falls is about 25 . For more information, see Korotev (2002).

The lunar surface has been traditionally divided into two major terranes, terra (or highlands) and maria. This division served us well for a long time. According to postApollo models, one abundant type of highland rock, called anorthosite, made up the initial lunar crust when feldspar crystallized from a globe-encircling ocean of magma and floated to the top to create huge masses of anorthosite. (Plagioclase feldspar constitutes more than $90 \%$ of anorthosites.) Other magmas subsequently intruded into this primary crust. Mare lavas formed by melting of accumulated dense minerals from the magma ocean, erupting from fissures, and flowing across the stark lunar surface.

However, things are not actually so simple, as the new global data show. There are prominent regions on the Moon defined by chemical characteristics, specifically by the concentrations of iron oxide and thorium, not only by morphology and color. Iron and thorium are particularly useful elements when distinguishing rock types from each other and in monitoring geochemical processes.

Jolliff et al. (2000) divide the lunar surface into chemically distinctive terranes. The Feldspathic Highlands Terrane (FHT) encompasses much of the lunar highlands and is characterized by low $\mathrm{FeO}$ (4.2 wt\% on average) and very low $\mathrm{Th}$ ( 0.8 parts per million). It is composed of anorthosite and related feldspar-rich rocks, and represents a relatively pure form of the ancient, primary lunar crust. FHT covers $65 \%$ of the lunar surface. Feldsparrich lunar meteorites have similar $\mathrm{FeO}$ and $\mathrm{Th}$ contents to the FHT, suggesting that the meteorites represent a reasonable average chemical composition of this important region of the lunar crust (Korotev 1999). Apollo granulitic impact breccias also provide a reasonable match to this region of the crust.

The Procellarum KREEP ${ }^{1}$ Terrane (PKT) dominates the nearside of the Moon. The PKT is a mixture of assorted rocks, including most of the mare basalts on the Moon, and is characterized by high Th (about 5 parts per million on average). This region has also been called the "high-Th Oval Region" and the "Great Lunar Hot Spot." PKT occupies about $16 \%$ of the lunar surface. How one region of the crust became so distinctive is unclear, but its concentration of radioactive elements $(\mathrm{K}, \mathrm{U}, \mathrm{Th})$ may have led to important thermal consequences, such as the location of most mare basalts on the lunar nearside (Wieczorek \& Phillips 2000).

A third distinctive terrane is the South Pole-Aitken terrane, associated with the huge (2500 km diameter) South Pole-Aitken basin. The inner part of this farside terrane has moderate $\mathrm{FeO}$ (average of $10.1 \mathrm{wt} \%$ ) and $\mathrm{Th}(1.9$ parts per million); its outer portion has less $\mathrm{FeO}(5.7 \mathrm{wt} \%)$ and $\mathrm{Th}$ (1.0 parts per million). Many lunar scientists have presumed that the entire lower crust of the Moon has a composition similar to that of the PKT, but the existence of terrane much lower in Th inside the huge South Pole-Aitken basin calls this into question.

${ }^{1}$ KREEP is an acronym for lunar rocks that are high in potassium, rare earth elements, and phosphorous. 
The integrated global data has been used to map the distribution of anorthosite in the lunar crust (Tompkins \& Pieters 1999). Although surprisingly sparse in abundance in the PKT Terrane, anorthosite is abundant elsewhere. A surprising discovery is that anorthosite has been identified in the rings of most nearside basins. This suggests that the anorthosites were exposed from beneath a near-surface layer. Haskin (1998) has argued that ejecta from the Imbrium basin are widespread and that there is a concentration of it antipodal to the impact site, creating an anomalous region in the northwestern part of the South Pole-Aitken basin. These and other studies illustrate the importance of impact basins in redistributing materials and complicating the picture of the early lunar crust.

Theoretical considerations led to the idea that water could be trapped in permanentlyshadowed regions near the lunar poles. The Clementine and Lunar Prospector missions and radar measurements with the Arecibo radio telescope appear to have confirmed the predictions (Nozette et al. 2001). Measurements by the Prospector neutron spectrometer show that concentrations of $\mathrm{H}$ are coincident with permanently-shadowed craters. However, the case is not closed. For example, we do not know if the $\mathrm{H}$ is in water ice or some other form, the total concentration, or the ultimate source, e.g. solar wind or comet impacts. More data are needed. Specifically, we need to make more thorough maps of the distribution of permanently-shadowed regions, search for ice and $\mathrm{H}$ concentrations with high-resolution synthetic aperture radar and neutron spectrometry, and land missions to determine the volatile species present.

The idea that the Moon suffered a dramatic increase in the rate of impacting bodies about 3.9 billion years ago (Tera et al. 1974; Ryder 1990) was given a boost from studies of impact-melted rock fragments in lunar meteorites. Data from Apollo and Luna samples indicate that there are no impact melts older than about 3.9 billion years. Since many of these samples were formed in basin-forming impacts, it suggests a narrow interval during which numerous basins might have formed. However, the Apollo and Luna samples were collected in a relatively narrow region of the Moon, and it has been argued that the ages refer to only a few basins. One way to test this idea is to date impact melts in lunar meteorites. Initial results suggest that impact melt rocks older than about 3.9 billion years are absent, suggesting a moonwide phenomenon (Cohen et al. 2000).

Many investigators have assumed that this bombardment affected the Earth as well, and that it must have affected the course of the origin and evolution of life. Some have suggested that the events were so severe that each sterilized the Earth, forcing life to begin anew. However, careful consideration of the effects of impact suggests that basin-forming events are not sterilizing. In fact, the impacts might even have been beneficial to the origin of life (Ryder 2002; Kring 2000).

\section{Mars Atmosphere}

\section{Michael D. Smith}

A large amount of new data about the Martian atmosphere has been obtained by the Mars Global Surveyor (MGS) spacecraft which entered mapping orbit in March 1999 and the Mars Odyssey spacecraft which entered mapping orbit in February 2002. Observations by the Hubble Space Telescope and ground-based observatories have also added significant new information.

Monitoring by the MGS Thermal Emission Spectrometer (TES) has allowed the mapping of the seasonal and spatial variations of atmospheric temperatures, aerosol dust and water ice optical depth, and water vapor column abundance (Smith et al. 2001). Images from the MGS Mars Orbiter Camera (MOC) have allowed detailed mapping of the occurrence of dust devils, dust storms, and water ice clouds (Cantor et al. 2001). The radio occultation experiment on-board MGS has provided complementary high vertical resolution temperature profiles at a limited number of locations. The Mars Odyssey Thermal Emission Imaging System (THEMIS) provides the capability of monitoring atmospheric temperatures and dust and water ice aerosol optical depth through visible and thermal 
infrared imaging. Ground-based and Hubble Space Telescope observations include tracking the seasonal, spatial, and diurnal variation of ozone and water vapor, and the characterization of dust and water ice aerosols at wavelengths from the infrared to the ultraviolet (Sprague et al. 2001; Klassen \& Bell 2002).

The most significant atmospheric event on Mars during the past few years was the planet-encircling dust storm of 2001. Ground-based and MGS observations were able to record in unprecedented detail the initiation, growth, evolution, and decay of the largest dust storm in 30 years. Observations from MGS TES in particular were able to map atmospheric temperatures and dust aerosol optical depth throughout the dust storm (Smith et al. 2002). On $26 \mathrm{June} 2001\left(\mathrm{~L}_{s}=185^{\circ}\right)$, a strong but local-scale dust storm to the northeast of Hellas basin began to grow explosively reaching planet-encircling status in about two weeks. Several areas of nearly contemporaneous dust lifting at different longitudes contributed to making the dust storm planet-encircling. By 1 August $2001\left(\mathrm{~L}_{s}=205^{\circ}\right)$ the dust storm had reached peak strength with infrared dust aerosol optical depth of 1-2 covering nearly everything south of about $40^{\circ} \mathrm{N}$ latitude. Atmospheric temperatures increased by more than $40 \mathrm{~K}$ from $20^{\circ} \mathrm{N}$ latitude to the south pole. Dust aerosol optical depth and atmospheric temperatures decreased back toward normal seasonal values on a time scale of about two months.

With nearly two full Martian years of data taken, the MGS TES and MOC data allow a direct measurement of interannual variability to be made. MGS observations show that the aphelion season (northern spring and summer) generally shows much less variability than the perihelion (southern spring and summer) season. Comparisons of MGS data with Viking orbiter data (Liu \& Richardson 2001) give similar results.

With the influx of high-quality data over the past few years there has been a corresponding increase in modeling and analysis efforts. At the largest spatial and temporal scales, general circulation models (GCM) developed for Mars have been used to model the current and past climate state of Mars. A fundamental hemispheric asymmetry in climate driven by the asymmetry in topography has been found to cause the southern summer cross-equatorial Hadley circulation to dominate the northern summer circulation regardless of the time relative to perihelion (Richardson \& Wilson 2002). GCM models are also being employed to explore the mechanisms that drive the water cycle and that cause the initiation and growth of large dust storms.

The study of waves and solar thermal tides has been a central topic of modeling and analysis efforts. The MGS TES data have been Fourier analyzed to catalog the different stationary forced wave modes present in the atmosphere as a function of season, latitude, and height (Banfield et al. 2001).

The introduction of mesoscale models of the Martian atmosphere, typically considering circulations on the scales of tens to hundreds of $\mathrm{km}$ has helped in understanding smallerscale circulations (Toigo \& Richardson 2002). This mesoscale modeling has played an important role in the selection process for the 2003 Mars Exploration Rover landing sites, and it will likely become increasingly important as high spatial resolution spacecraft data are used to their full potential.

The large and continuous input of new data that continues to be collected from groundbased observatories, the Hubble Space Telescope, and the MGS and Odyssey spacecraft is providing unprecedented detail about the current state of the Martian atmosphere. Data returned by Mars rovers and orbiters planned for the near future will provide additional complementary data. Modeling and analysis efforts using these new data give the opportunity to greatly improve our understanding of the underlying physical processes that control the structure, dynamics, dust cycle, and water cycle in the Martian atmosphere. 


\section{Mars: Geologic Evidence for Water}

\section{Kenneth S. Edgett}

Mars has water. It is in the atmosphere, and it comprises the frost of the residual north polar cap. Meteorites believed to be from Mars also contain water and mineralogical evidence for water. Mariner 9 images revealed a plethora of land forms considered by most to have formed by liquid water, particularly networks of valleys in the cratered highlands and tremendous channels that may have been carved by catastrophic floods. Later Viking images provided evidence that permitted speculation that Mars might have also had lakes, seas, even oceans. Prior to 2000-2002, the best geologic evidence that water once flowed on Mars came from images acquired by the Mars Pathfinder lander in 1997. Near the lander is a field of imbricated rocks, a telltale sign that a fluid with all of the physical properties of water once passed through the site.

Two seminal papers regarding evidence for past action of liquid water on Mars were published in 2000-2002 (Malin \& Edgett 2000 a,b). Both reported new results from the Mars Global Surveyor (MGS) Mars Orbiter Camera (MOC). MGS began orbiting Mars in September 1997; its primary mission ran March 1999 through January 2001, and an extended mission is underway. The features that are the subject of the Malin \& Edgett (2000 a,b) papers also appear in new images, obtained since February 2002, by the Mars Odyssey Thermal Emission Imaging System (THEMIS).

The MOC acquires pictures with spatial resolutions of 1.5 to $12 \mathrm{~m} /$ pixel. By virtue of this resolution, higher than attained by previous spacecraft, a new landform was discovered: the middle-and polar-latitude gully (Malin \& Edgett 2000a). The gullies occur $\sim 2: 1$ on poleward-facing slopes at middle and high latitudes; these associations imply involvement of a volatile responsive to insolation. Banked, leveed, and anastomosing channels indicate that transport involved a fluid with the properties of liquid water; multi-lobed aprons indicate multiple depositional phases or events. Most gullies are geologically young; most are uncratered, not mantled by dust, and have channels that cut aprons and superpose most surrounding land forms. Although $\mathrm{CO}_{2}$, shallow ground ice, or snow melt are proposed alternatives (e.g., Musselwhite et al. 2001; Costard et al. 2001), the most likely source of fluid is groundwater, whether in the form of fresh water, brine, or frozen water that melts under certain conditions (Malin \& Edgett 2000a; Mellon \& Phillips 2001; Knauth \& Burt 2002). A groundwater source is indicated not only by gully morphology, but by occurrence of regional clusters and associations with a specific layer (or layers) at a given location. The latter two observations are attributes of aquifers (Malin \& Edgett 2000a; 2001).

Prior to MGS, finding sedimentary rocks on Mars emerged as a high-priority in the search for ancient lacustrine or marine environments that might have been conducive to life. MOC images have affirmed the likely presence of sedimentary rocks on Mars (Malin \& Edgett 2000b). These hard, cliff-forming materials are found in depositional settings and in geologic configurations that, if they occurred on Earth, would be interpreted to indicate locations of past bodies of water. Some of the outcrops, which tend to be light-toned and layered, were known from Mariner 9 and Viking images.

Pictures from MOC, particularly of outcrops in the Valles Marineris and craters in western Arabia Terra, reveal hundreds of repeated beds of similar thickness and physical properties (Malin \& Edgett 2000b). Each repeated layer is $10 \mathrm{~m}$ thick. Most are located many thousands of kilometers from volcanic regions, and most are in ancient impact craters. Beds with these properties, on Earth, would without question have been interpreted as having been deposited in subaqueous environments. Malin \& Edgett (2000b) proposed that, if they were not deposited in water, then they must have formed in a subaerial environment that was unique to early Mars, an environment in which deposition would mimic that of subaqueous processes.

Others have suggested that tephra (clasts produced by explosive volcanism), exclusively, could have formed the layered material (Chapman \& Tanaka 2002; Hynek et al. 2002), but these authors did not address the specific characteristics of the repeated beds 
observed in MOC images. The layered outcrops have mappable stratigraphies, include erosional unconformities (exhumed channels and craters, in some cases), and are found at hundreds of locations scattered around the planet (Malin \& Edgett 2000b; 2001). Some, as in Holden Crater $\left(26^{\circ} \mathrm{S}, 34^{\circ} \mathrm{W}\right.$ ), have been cut and eroded by a fluid (e.g. water) at some time in the distant past, implying that the layers, themselves, are extremely ancient and likely represent a record of early Martian environmental conditions.

A third, important suite of results emerged from the MGS Thermal Emission Spectrometer (TES) experiment. For water, the most important result from TES is a negative result, the non-detection of carbonates. No outcrops of limestone or dolomite were identified in TES spectra (Christensen et al. 2001a; Bandfield 2002), although it remains possible that the physical nature of carbonate outcrops, including dissolution pits, chemical alteration, and mantles of silicate dust, might obscure these materials (e.g. Kirkland et al. 2001). Equally possible, carbonate outcrops may be too small to be resolved in the $3 \times 3 \mathrm{~km}$ spots observed by the TES detectors, but may eventually be found using the higher-resolution (100 m/pixel) THEMIS instrument.

In addition to the carbonate result, TES spectra show occurrences of olivine, including some that might be in very ancient rocks (Christensen et al. 2001a; Bandfield 2002). Olivine is more readily altered in the presence of water than other silicates such as pyroxenes and feldspars. The presence of olivine in ancient outcrops, along with the non-detection of carbonate, suggest water may not have played a large role in chemical weathering on Mars. In contrast, the TES experiment also revealed large surface exposures of gray hematite, which to some investigators is a clear indication of a role for water in mineralization on Mars (Christensen et al. 2000 2001b; Allen et al. 2001).

With the advent of TES spectra, over 125,000 MOC images, and the new THEMIS data, hundreds of papers and extended abstracts on the subject of water on Mars have been published in the 2000-2002 period. Some have focused on creation of gullies, channels, and other land forms by alternative fluids, such as $\mathrm{CO}_{2}$ and methane (Hoffman 2000; Max \& Clifford 2000). Others have posed questions regarding the distinction between lava flows and mud flows in the Kasei, Marte, and Athabasca Valles regions (Kesztheyli et al. 2000; Malin \& Edgett 2001; Rice et al. 2002; Williams et al. 2002). Still others propose that water may have erupted from fissures in places like eastern Cerberus and Olympica Fossae to produce flood channels (Burr et al. 2002a,b; Berman \& Hartmann 2002).

Very little information about the primary processes that formed ancient valley networks has been preserved (Carr \& Malin 2000; Malin \& Edgett 2001), but researchers continue to explore their genesis and implications (e.g., Grant 2000; Aharonson et al. 2002). Researchers continued to examine whether the martian northern plains were once the site of an ocean; MOLA observations seemed to lend credibility to the hypothesis (Head et al. 1999), but MOC images showed no coastal landforms at the locations that had been identified by previous proponents of the hypothesis (Malin and Edgett 1999; 2001).

Geologic evidence for ground ice has centered on identification and speculation regarding possible periglacial land forms at middle and high latitudes (Malin \& Edgett 2001; Siebert \& Kargel 2001; Mustard et al. 2001). MOC images of north polar layers reveal a specific stratigraphy that includes sand and may imply that less water is present in these materials than previously believed (Malin and Edgett 2001; Byrne \& Murray 2002). Meanwhile, the south polar residual cap exhibits spectacular mesa formation and scarp retreat rates of $\sim 3 \mathrm{~m} /$ year, implying and confirming that these materials are $\mathrm{CO}_{2}$, not water (Malin et al. 2001).

\section{Mars: Geochemical Evidence for Water}

\section{William V. Boynton}

Much of the evidence for water on Mars comes from interpretations of photogeologic data, discussed above. The geochemical evidence concerning water on Mars comes from a few spacecraft missions and from ground-based study of Mars samples delivered to us in the 
form of meteorites. Unfortunately the Mars Polar Lander mission crashed at the end of 1999; had it succeeded, it would have provided a direct determination of the water content of the regolith in the south polar layered terrain (Boynton et al. 1999).

Recent measurements of the redox state of Martian meteorites suggest, even if indirectly, that the Martian crust may have contained water that served as an oxidation source for the magmas from which the basalts formed. Wadhwa (2001) determined the oxygen fugacity of several Martian basalts based on the $\mathrm{Eu}^{+2} / \mathrm{Eu}^{+3}$ redox couple. She noted the oxidation state correlated with ${ }^{87} \mathrm{Sr} /{ }^{86} \mathrm{Sr}$ and ${ }^{143} \mathrm{Nd} /{ }^{144} \mathrm{Nd}$ ratios and suggested that the basalts formed in a reducing environment in the upper mantle and were subsequently oxidized by assimilation of water-rich crustal material. Similarly, Herd et al. (2002) determined the oxygen fugacity from the nature of $\mathrm{Fe}-\mathrm{Ti}$ oxides in several Martian basalts and also suggested that the most reduced system was representative of the primary magma, and that the more oxidized basalts may have been altered by assimilated material that contained significant amounts of water.

McSween et al. (2001) studied pyroxenes in the Martian meteorite Shergotty, and compared them to pyroxenes made in laboratory experiments with different water contents. They concluded that the primary magma at depth may have had as much as $1.8 \%$ water at depth, but that this water was lost in the lower pressure environment as the magma rose to the surface. They note that the age of Shergotty, $175 \mathrm{Ma}$, suggests that magmas were delivering significant water to the surface even in middle Martian history.

Another line of indirect geochemical evidence for water on Mars comes from a reexamination of the infrared spectra returned by the TES on the Mars Global Surveyor mission. These data were originally interpreted as showing two distinct regions: a basaltic region in the older highlands in the south, and an andesitic region in the younger lowlands in the north (Bandfield et al. 2000). More recently, however, Wyatt and McSween (2002) reinterpreted the data as showing a basaltic region in the south and a region of aqueously altered basalt in the north. They excluded a high-silica glass from the mix of possible minerals to fit the observed spectra and found that their model described the spectra equally well. The differences between the two works is that the former model had high abundances of plagioclase and high-silica glass and low abundances of pyroxene and weathering products, whereas the latter model had plagioclase, an appreciable amount of alteration minerals, and less pyroxene.

If the Wyatt and McSween model correctly describes the minerals in the northern lowlands, it could be evidence for aqueous alteration of basalts. There is no good rationale for choosing one model over another on the basis of the quality of the fit, but Wyatt and $\mathrm{McSween}$ (2002) argued that it is difficult to imagine how to make such large quantities of andesite under Martian conditions and thus favored the model with significant amounts of weathering products.

Geochemical evidence for water on Mars that is much more direct came from the 2001 Mars Odyssey Mission. The Gamma-Ray Spectrometer found evidence for large quantities of hydrogen, especially in the south polar regions (Boynton et al. 2002; Feldman et al. 2002; Mitrofanov et al. 2002).

The region south of $-45^{\circ}$ latitude was analyzed in detail by Boynton et al. (2002) who found that when the flux of epithermal neutrons, thermal neutrons, and hydrogen gamma rays were all considered together, the results indicated that the near surface of Mars contained hydrogen in high abundance, $35 \% \pm 15 \% \mathrm{H}_{2} \mathrm{O}$ equivalent by weight. This hydrogen-rich soil was not on the surface but was buried beneath a relatively hydrogen-poor layer that ranged in thickness from about $1 \mathrm{~m}$ at $-45^{\circ}$ latitude decreasing to about $30 \mathrm{~cm}$ at $-75^{\circ}$ (assuming a regolith density of $1.25 \mathrm{~g} / \mathrm{cm}^{3}$ ). They argued that the observed high quantity of subsurface hydrogen in the polar region was in the form of water ice. The bases of their arguments were the large amount of hydrogen, the fact that it was greatly enriched beneath the surface, and the fact that it correlated strongly with regions where ice has been predicted to be thermodynamically stable at depth (Mellon \& Jakosky 1993). They 
indicated that the large ice abundance in the subsurface material is at or it exceeds the limit expected for filled pore space in dry soil.

Feldman et al. (2002) reported other areas of enhanced subsurface hydrogen in equatorial regions. The amount of hydrogen was substantially less than that in the polar regions, about $4 \%$ water equivalent buried beneath a $15-20 \mathrm{~cm}$ hydrogen-poor layer. Ice is not thermodynamically stable at these latitudes, so the hydrogen is almost certainly present in a more stable, chemically-bound form of water.

With the recent geochemical evidence for significant amounts of near-surface ice and the very detailed photogeologic data providing other evidence of water and ice, our understanding of the role of Martian water should improve considerably. Assuming the vigorous Mars exploration planned for the future will occur, our understanding should increase significantly. Mars has clearly had a very complex history with respect to water (Baker 2001), and it will clearly require a combination of orbital, landed, and sample-return missions to get an adequate understanding of the role water has played in Martian history.

\section{Io Volcanism}

\section{R. M. C. Lopes}

The five successful close fly-bys of Io by the Galileo spacecraft during 1999-2001 have brought major advances in our understanding of Io. (Unless otherwise referenced, the sources for the information which follows are papers in McEwen 2001). For the first time, Io's many volcanic regions were observed at high spatial resolution by Galileo's remote sensing instruments, with wavelength coverage from the visible to the infrared. Observations by Galileo's particles and fields instruments studied the hostile environment around Io, and observations from the Earth complemented those from the spacecraft. Gravity measurements from tracking of the Galileo spacecraft indicate that Io has a large iron or iron/iron sulfide core, comprising $\sim 20 \%$ of the satellite's mass, as previously predicted (Consolmagno 1981). One of the major discoveries from the fly-bys is that lo lacks a strong intrinsic magnetic field, suggesting little core convection (Kivelson et al. 2001).

Io has many more active volcanoes than had been detected before the fly-bys. The closer Galileo got to Io's surface, the more hot spots were revealed. At least 120 hot spots are now known, and is estimated that some 300 may be present. These hot spots appear to have a fairly uniform distribution on the surface, consistent with numerical simulations of convection in Io's asthenosphere. The volcanic hot spots account for most of the heat flow, which is largely radiated at wavelengths $>5 \mu \mathrm{m}$ (Veeder et al. 1994).

Galileo observations obtained the first hemispheric maps of broadband night-time emission (Spencer et al. 2000b) which showed that temperatures away from the known hot spots are near $95 \mathrm{~K}$ and are independent of latitude and local time. The lack of falloff in temperature with latitude implies that volcanic activity may be present at high latitudes, even though discrete hot spots have not been detected at latitudes $>65^{\circ}$. Galileo measurements led to a new estimate of Io's average heat flow of $1.7 \mathrm{Wm}^{-2}$ (Spencer et al. 2000b). The current upper limit is $\sim 13 \mathrm{Wm}^{-2}$.

One of the most important findings from Galileo was the detection of very high temperature lavas from the Pillan hot spot in 1997 during a vigorous eruption (McEwen et al. 1998b). These lavas ( $>1800 \mathrm{~K}$ ) were interpreted as possibly komateiitic in composition (ultramafic lavas rich in magnesium), similar to those emplaced on Earth in ancient times (mostly $>2$ billion years ago). Studies of eruption mechanisms on fo are therefore relevant to studies of the early Earth. It is possible that most, perhaps all, hot spots on Io erupt very high temperature lavas. However, because lavas cool off quickly, temperatures close to that of the liquidus are hard to detect. A second measurement of ultramafic-range temperatures on Io was made from high-resolution observations of the hot spot Pele during the Galileo flybys. 
High-resolution observations and temporal data on Io's hot spots showed that some broad generalizations can be drawn about eruption style. The majority of Ionian eruptions can be placed in three classes: Promethean, Pillanian, and lava lakes. A single hot spot can exhibit more than one eruption style over time. Data from the Galileo fly-bys showed that lava lakes are abundant on Io and they may be a significant mechanism for heat loss from the interior. Io's most powerful hot spot, Loki, is thought to be a giant lava lake that undergoes periodic overturning, leading to brightenings that have been observed from Earth for decades (Rathburn et al. 2002). Many other hot spots on Io appear to be persistent lava lakes, perhaps indicating open systems such as those in some volcanoes on Earth (Lopes-Gautier 1999).

Pillanian type eruptions have an intense, short-lived phase that may correspond to the outbursts detected from Earth (e. g. Stansberry et al. 1998). Large plumes are associated with these eruptions. Their vast plume deposits can significantly change Io's appearance and are probably a major factor in resurfacing.

Promethean type eruptions, less intense but more persistent than the Pillanian type, are named after the Prometheus hot spot. It has a persistent plume about $100 \mathrm{~km} \mathrm{high,}$ active during both Voyager encounters in 1979 and throughout the Galileo mission. Surprisingly, distant images obtained by Galileo in 1996 showed that the Prometheus plume site had moved about $80 \mathrm{~km}$ west since 1979 (McEwen et al. 1998a), but its size and appearance had not changed. A new lava flow linked the old and new plume sites. Images and infrared observations obtained in 1999 showed that the main vent of this volcano was near the Voyager plume site and that the plume, not the volcano, had moved west (McEwen et al. 2000, Lopes-Gautier et al. 2000).

The plume's movement was modeled in terms of the interaction between the advancing hot lava and the underlying $\mathrm{SO}_{2}$ snowfield (Kieffer et al. 2000). The movement of lava flows on Earth over marshy ground can give rise to small, short-lived explosive activity, but nothing on the scale of the Prometheus plume has ever been observed. Perhaps this type of eruption is common on Io; and once the flow stops moving, the plume eventually shuts off, as has been observed at Amirani.

Io's plumes are spectacular manifestations of volcanism. One of the last surprises from Galileo observations was the detection of four large plumes at high northern latitudes. Prior to 2000 , there was no detection of high latitude plumes by Galileo, though deposits on the surface indicated that plume activity had occurred in the past. The largest plume known on Io (500 km high) was detected from images obtained in August 2001, shortly after the Galileo spacecraft had flown through it. Observations by the plasma science experiment indicated the presence of $\mathrm{SO}_{2}$ molecules in the plume (Frank \& Paterson 2001). This in-situ measurement is consistent with others that show the presence of $\mathrm{SO}_{2}$ in plumes (e.g. Pearl et al. 1979) and $\mathrm{SO}_{2}$ frost in plume deposits (e.g. Lopes-Gautier et al. 2000; Douté et al. 2001). Sulfur $\left(\mathrm{S}_{3}\right.$ and $\left.\mathrm{S}_{4}\right)$, in addition to $\mathrm{SO}_{2}$, was detected in the Pele plume from measurements made from the Hubble Space Telescope (Spencer et al. 2000a).

Sulfur dioxide, condensed from volcanic plumes, blankets Io's surface (Carlson et al. 1997; Douté et al. 2001) and hinders detection of other species. The abundance and grain sizes of $\mathrm{SO}_{2}$ are variable over the surface (Douté et al. 2001). A broad absorption at about 1 $\mu \mathrm{m}$, as yet unassigned (Carlson et al. 1997) is anti-correlated with recently emplaced lavas. Local patches of almost pure $\mathrm{SO}_{2}$ were detected, in one case topographically confined, raising the possibility that it was emplaced as a fluid (Smythe et al. 2001). The possibility that Io has sulfur flows in some areas remains, but no definite evidence has been found.

Io's volcanoes tend to be topographically low. Jagged mountain peaks up to $17 \mathrm{~km}$ high are present, but the mountains appear unrelated to the active volcanoes. Many mountains appear to be tilted crustal blocks raised by thrust faulting. Mass wasting also occurs, contributing to the active surface geology.

The Galileo mission ended its observations of Io in 2001, but observations from the Hubble Space Telescope and from ground-based instruments continue. Significant advances have been made in the use of adaptive optics to observe Io's volcanic activity (Marchis et 
al. 2000). It is expected that these observations will continue monitoring the temporal evolution of some of Io's hot spots.

\section{Geology of Galilean Satellites}

\section{Jeffrey $M$. Moore}

In the last three years our understanding of the geology of the Galilean satellites has continued to advance as the Galileo mission continued to collect data on these objects into late 2001. The planet-sized Galilean satellites-Callisto, Ganymede, Europa, and Io-among them exhibit geological process of volcanism, tectonism, impact cratering, and mass wasting. However, the extent of the expressions and combinations of these processes varies dramatically among them. Much of the new Galilean satellite paradigm emerged in the previous three years prior to 2000 from the Galileo Primary Mission and Galileo Europa Mission. Late mission observations have provided additional strength to earlier Galileo-era findings, and additionally, opportunities to closely observe the intensely volcanic moon Io occurred during this time (see above).

Late mission studies of Callisto found large-scale anisotropies in the distribution of $\mathrm{SO}_{2}$ and $\mathrm{CO}_{2}$ on its surface. A tenuous $\mathrm{CO}_{2}$ atmosphere on that moon was also reported (Carlson 1999). The discovery of an induced magnetic field at Callisto suggests the presence of a conducting subsurface layer which has been interpreted to be evidence for a subsurface zone of liquid water, about $10 \mathrm{~km}$ thick and occurring at a depth of less than $300 \mathrm{~km}$ but probably at greater than $100 \mathrm{~km}$ (Anderson et al. 2001b).

Given Callisto's apparent lack of internal heating as implied by the lack of endogenic features on its surface, initial suggestions for how such a layer of liquid could survive into the present employ contaminants which would significantly depress the freezing point, such as salts or ammonia. Alternative explanations are that the highly anisotropic behavior of ice viscosity as a function of temperature, pressure, grain size, and stress prevent the ice overlying the liquid layer from convecting, thus preventing enough heat loss to freeze the layer (Ruiz 2001). Several recent topical studies of surface geology have focused on largescale mass movements (e.g., landslides), the formation of the ubiquitous kilometer-scale knobs covering its landscape, and the evolution of impact craters.

Late mission Galileo magnetometer analysis of Ganymede strongly suggested that this moon too possesses an induced magnetic field in addition to its intrinsic dipole field, implying that it, like Callisto, has a subsurface zone of liquid water a few $\mathrm{km}$ thick and occurring at a depth on order of $150 \mathrm{~km}$, sandwiched between layers of ice (Kivelson et al. 2002).

The idea that some, if not much, of Ganymede's bright terrain is formed by the cryovolcanic (watery) eruptions onto the surface, popular after the 1979 Voyager encounters but questioned by early Galileo results, regained significant credibility (Schenk et al. 2001a). Topographic relief models, produced by using Voyager and Galileo images as stereo-pairs, revealed smooth swaths hundreds of kilometers long and tens of kilometers wide that were at constant elevation. Watery "lavas," now solidified, easily and best explain such an equipotential surface. As most, but not all, bright terrain is to some extent tectonized, it is reasonable to infer that low-viscosity cryo-volcanic extrusions and tectonism usually operate in concert. Conversely it is probable that some bright, but very rugged, terrains were formed and brightened by tectonism alone.

Recent Europa research tends to support the model of an ice layer more than $10 \mathrm{~km}$ thick overlying a water layer on order of $100 \mathrm{~km}$, which in turn rests upon a rocky floor, making Europa probably the only other place in the Solar System with something akin to the Earth's oceans. Several recent studies of the shapes of large impact features on Europa conclude that its ice layer must, at the very least, be 3-4 km thick and probably closer to $20 \mathrm{~km}$ (Moore et al. 2001; Turtle \& Peirazzo 2001; Schenk 2002). Strong geologic evidence for ice convection indicates an ice layer thickness of at least $10 \mathrm{~km}$. 
Late mission Galileo magnetometer analysis of Europa provides the strongest, nearly conclusive, evidence that there is an "ocean" under the ice layer (Kivelson et al. 2000). With the near certainty of the ocean, speculation and research has now turned to that water body's potential as an abode of life. The enigmatic reddish material coating portions of Europa's surface has been variously interpreted using NIMS data to be composed of salts or sulfuric acid (Carlson et al. 1999). This material is at any rate thought to be sulfur bearing. Several studies have looked into various means of generating and renewing chemicals that are necessary for metabolism and delivering them to the ocean (Chyba \& Hand 2001). Bear in mind, however, that there is currently no evidence for life on Europa.

Gravity measurements of Io, most of which were acquired during late-mission Galileo close-encounters, indicate that it has a large iron or iron/iron sulfide core, representing $\sim 20 \%$ of that satellite's mass (Anderson et al. 2001a). However, no significant intrinsic magnetic field was detected, suggesting that this core is not vigorously convecting (Kivelson et al. 2001). The outer shell is thought to be dominated by silicates, within which might exist a "magma ocean."

Galileo data, and new ground-based observations, indicate that much of the volcanism on Io is silicate rather than low-temperature sulfurous flows as was thought by many researchers following the Voyager encounters. Indeed, observations of short lived large eruptions of very high temperature materials approaching $2000 \mathrm{~K}$ and seen forming fire curtains were fortuitously captured (McEwen et al. 2000). Silicate lava flows encroaching on a landscape with near-surface reservoirs of $\mathrm{SO}_{2}$ ice were observed to be the source of long lived plume eruptions whose plume base slowly migrates with the advancing flow front (Milazzo et al. 2001). Elsewhere a few volcanic flows appear to be either dominantly composed of sulfur or else coated with sulfur. These flows, if truly sulfur, presumably are the result of the melting and remobilization of sulfur deposits by underlying silicate magma.

Io's topography is dominated by plains punctuated by quasi-randomly distributed caldera depressions and tall non-volcanic mountains (Schenk et al. 2001b). The mountains possibly form by stresses induced by crustal cycling (Turtle et al. 2001; McKinnon et al. 2001). Not a single impact crater has been unambiguously identified on Io even in images with resolutions of $<10 \mathrm{~m} /$ pixel, implying a volcanic globally averaged resurfacing rate of at least $0.5 \mathrm{~mm} / \mathrm{yr}$ (Phillips 2000).

\section{Outer Jovian Satellites}

\section{Scott Sheppard}

During the years of 1999-2002 a revival in the study of Jupiter's outer satellites has occurred. Recently 22 new irregular satellites (satellites with large semi-major axes, inclinations, and eccentricities) were discovered around Jupiter (Sheppard et al. 2000, Sheppard et al. 2001, Sheppard et al. 2002). Twenty of these satellites join 5 others known that have retrograde orbits with semi-major axes near 300 Jupiter radii $\left(R_{J}\right)$ and inclinations of about $155^{\circ}$; one falls into a prograde group with 4 other known satellites with semi-major axes near $150 R_{J}$ and inclinations near $25^{\circ}$; and the other discovered satellite has a prograde orbit in which it is the lone member with semi-major axis of about $100 R_{J}$ and inclination of $45^{\circ}$.

There may be dynamical subgrouping in the retrograde group indicating multiple parent bodies or orbital evolution of the satellites. All 31 known outer satellites of Jupiter are believed to have been captured by Jupiter very early in Solar System history either through gas drag, collisions, or mass growth of the planet. About 100 irregular satellites with diameters $>1 \mathrm{~km}$ are expected around Jupiter. Their size distribution is much shallower than that of known asteroid families or expected from equilibrium collisional evolution.

Currently all the giant gaseous planets seem to have comparable numbers of irregular satellites. Any theory of the formation mechanisms of these planets needs to account for these similarities. 
Optical colors of the 8 brightest outer satellites of Jupiter show that the prograde group appears redder and more tightly clustered in color space than the retrograde irregulars (Rettig et al. 2002). These color differences between the groups are expected if they each formed from the breakup of different parent bodies. Near-infrared colors recently obtained of the brighter satellites agree with this scenario. The objects' colors are consistent with D and C-type asteroids (Sykes et al. 2000).

Near-infrared and optical spectra of the brightest satellites are mostly featureless (Brown 2000; Jarvis 2000; Brown 2002). Jarvis finds a possible $0.7 \mu \mathrm{m}$ absorption feature in Himalia and attributes this to oxidized iron in phyllosilicates which is typically produced by aqueous alteration. The spectra are consistent with C-type asteroids.

Jacobson (2000) applied numerically integrated orbital fits using all reported observations up to January 2000 of the 8 outer satellites known prior to 2000 , and described the orbital properties of these 8 satellites. The detection of dust in bound orbits about Jupiter in the outer Jupiter system by the Galileo spacecraft has been attributed to high velocity impacts of interplanetary micrometeoroids into the atmosphereless outer satellites (Krivov et al. 2002). Carruba et al. (2002) demonstrated that all the known irregular satellites of Jupiter have orbits near the equatorial plane of Jupiter because of the destabilizing Kozai effect.

\section{Magnetosphere of Jupiter As Seen by Cassini}

\section{Philippe Zarka}

Cassini flew by Jupiter on 30 December 2000. In spite of the large closest approach distance $\left(137 \mathrm{R}_{J}\right.$, i.e. about $\left.10^{7} \mathrm{~km}\right)$, important results on the Jovian magnetosphere were obtained thanks to the sophisticated instrumentation carried by Cassini and the opportunity to perform coordinated measurements with the Galileo orbital mission as well as with Earth-orbiting telescopes (Hubble and Chandra) and ground-based radiotelescopes (VLA, Nançay).

A central question about the magnetospheric dynamics concerns its control by internal processes like planetary rotation, or external ones like solar wind compressions. Order of magnitude estimates suggest that corotation dominates by about a factor of 10 , and that externally-driven magnetospheric activity should be correlated with magnetospheric expansions (Southwood \& Kivelson 2001). The existence of a solar wind influence has been demonstrated by numerous studies of radio and UV observations of the aurora, while the analysis of Galileo data has revealed the existence of bursts of magnetospheric activity possibly correlated with centrifugal ejections of plasma from Io's torus (Louarn et al. 2000).

During the Cassini flyby, three interplanetary shock waves happened to strike and compress Jupiter's magnetosphere, where they caused intensifications of radio and possibly UV emissions (Gurnett et al. 2002), in contradiction with the predictions of Southwood \& Kivelson (2001). A more quantitative study of the relative influence of rotation and solar wind on Jupiter's magnetosphere requires continuous global observations over a duration longer than that of the studied phenomena (several months), so as to dissociate the involved time-scales. Such observations could be the goal of a dedicated microsatellite.

The simultaneous presence of Cassini and Galileo near Jupiter also allowed researchers to perform two-point measurements of the location of the magnetopause and of its response to solar wind compressions. Kurth et al. (2002) found that these measurements were incompatible with a simple, convex magnetopause shape. They concluded that the magnetosphere was actually observed in the middle of a contraction process due to the passage of high pressure solar wind, leading to a more complex shape composite of a compressed magnetopause on the dayside and a less compressed one towards the tail. The data also showed evidence for a thick boundary layer just inside the magnetopause.

Ultraviolet observations by the Hubble Space Telescope at the time of the Cassini fly-by shed a new light on the electrodynamic interaction between the Galilean satellites 
and Jupiter's magnetic field. In particular, Clarke et al. (2002) observed that faint trails of UV emission follow the main spot near the footprints of Io, Ganymede and Europa, suggesting that the interaction between these moons and the magnetosphere "relaxes" (for example through wake plasma re-acceleration) during several tens of degrees in longitude (corresponding to 1-2 hours). Hospodarsky et al. (2001) showed that a control by Io, Ganymede and Callisto is detectable in Jupiter's radio emissions observed by Galileo and Cassini. The absence of control by Europa, as well as the absence of UV spot for Callisto, remain to be explained.

Observations by the X-ray satellite Chandra revealed a pulsating northern auroral Xray hot spot on Jupiter, with a pulsation period about 45 minutes (Gladstone et al. 2002). The spot location suggests that the origin of the precipitating energetic particles is in the outer magnetosphere, rather than in the inner magnetosphere as previously thought. The pulsation is similar to that of some radio bursts and energetic particle fluxes observed by Ulysses, and could be associated with ULF standing waves in the outer magnetosphere.

On 2-3 January 2001, the radiometer of the Cassini radar experiment, connected to the spacecraft high-gain antenna, was used to map the synchrotron emission of Jupiter's radiation belts at a wavelength of $2.2 \mathrm{~cm}(13.8 \mathrm{GHz})$. Such high frequencies are poorly accessible from the ground due to confusion with thermal emission. Cassini maps at 2.2 $\mathrm{cm}$, made simultaneously with maps from the Very Large Array at 20 and $90 \mathrm{~cm}$, showed that electrons with energies up to $50 \mathrm{MeV}$ are present in Jupiter's inner magnetosphere, and that electrons with energies $\sim 20 \mathrm{MeV}$ are more abundant than previously thought (Bolton et al. 2002). Explaining the acceleration of these electrons is a difficult challenge.

Conversely, the morphology of the Jovian synchrotron sources is now well explained by a model of Jovian electron radiation belts developed by Santos-Costa and Bourdarie (2001). Variation of the synchrotron emission in conjunction with the solar wind is under study.

The Cassini magnetospheric imaging experiment carries the first energetic neutral atoms (ENA) camera ever used near Jupiter. During the fly-by, it obtained ENA images of Jupiter's environment, revealing a fast $(>1000 \mathrm{~km} / \mathrm{s})$ and hot isotropic neutral wind and a colder equatorial wind escaping from Io's torus (at $\sim 75 \mathrm{~km} / \mathrm{s}$ ) after charge exchange (Krimigis et al. 2002). Some of these neutrals are re-ionized and re-assimilated in the solar wind (so-called "pick-up" ions). The solar wind loading with Iogenic plasma can be detected to very large distances (several $\mathrm{AU}$ ).

Finally, during an extended period around the Cassini fly-by, high-sensitivity/highresolution measurements were performed by the radio experiment onboard Cassini, which helped document the complex fine structures morphology of Jovian radio components (Kurth et al. 2001; Lecacheux et al. 2001). These observations complement at low frequencies the studies performed with ground-based radiotelescopes on so-called "S"-bursts from the Io-Jupiter flux tube (Queinnec \& Zarka 2001), the origin of which is still not well understood.

\section{Aurorae of Jupiter and Saturn}

\section{Renée Prangé}

The last three years have seen a major development of theoretical modeling of magnetospheric auroral processes, and of coordinated observations and analysis of remote sensing of Jovian auroral emissions, particularly with the Hubble Space Telescope, with in-situ measurements in the Jovian magnetosphere by the particle-and-field instruments onboard Galileo, and more recently onboard Cassini. High spatial resolution far ultraviolet (FUV) images had formerly revealed a very complex auroral structure. This new coordinated approach has allowed us to identify the precipitating particle source in the equatorial magnetosphere for most of the auroral features, and to estimate the degree of control of the precipitating mechanisms by internal processes (rotation of the planet, Io plasma source) and by external processes (interaction with the solar wind). 
The main auroral oval, just poleward of the auroral footprint of Ganymede (Clarke et al. 2002), is magnetically connected to the partially-corotating plasma sheet between $\sim 20-50 \mathrm{R}_{J}$ and its locus is indeed fixed in longitude with the planet, even when observed from the nightside (Vasavada et al. 1999). Evidence of a "bean-like," highly distorted shape of the northern main oval rotating with Jupiter highlights the existence of a strong surface magnetic anomaly (Pallier \& Prangé 2001), not yet accounted for by current magnetic field models (Satoh \& Connerney 1999), and confirms the role of internal processes.

However, the intensity distribution exhibits a steady dawn-dusk asymmetry related to the asymmetry of the magnetosphere (i.e. plasma sheet thickness, field-aligned current direction), which indicates that the influence of the solar wind can penetrate, even if indirectly, quite far into the Jovian magnetosphere (Pallier \& Prangé 2001). Self-consistent modeling of the middle-magnetosphere plasma parameters has led to a realistic picture of the field-aligned current system triggered by the plasmasheet lag to rigid corotation, and of the subsequent energetic particle losses, as well in radial distance as in intensity (Cowley \& Bunce 2001; Bunce \& Cowley 2001a,b). These studies, together with Southwood \& Kivelson (2001)'s ones, predict an anticorrelation between the auroral activity and the solar wind pressure, which is not observed.

By contrast, clear increases of the overall auroral emission were recorded in the radio and EUV spectral range during the Galileo-Cassini campaign in response to the passage of an interplanetary shock measured by Cassini upstream of Jupiter (Gurnett et al. 2002). Long term monitoring of the global auroral activity in the FUV and at radio wavelengths has revealed a correlated modulation of the auroral output on time scales of the order of a few days (Prangé et al. 2001).

This modulation applies also to a number of physical parameters in the magnetosphere, such as the local plasma density, plasmasheet thickness, magnetic field behaviour, and nKOM emissions from the Io plasma torus (Louarn et al. 2000). Louarn et al. (2001) suggest an interesting scenario of bursty plasma transport from the Io torus to the middle magnetosphere including recurrent energy relaxation episodes via auroral particle precipitation and "energetic particle injection events" (Mauk et al. 2002). Whether this process is ultimately triggered internally or by a solar wind effect is still unclear, and it illustrates the complexity of the auroral processes of Jupiter.

Equatorward of the main oval, many HST images have shown auroral-type emissions at the footprints of Io, Europa and Ganymede (Clarke et al. 2002). This reveals that all three moons are connected to the Jovian ionosphere by field-aligned currents. The footprints of Europa and Ganymede are much fainter than Io's one, and at times not detectable. Their presence or absence may help identify the physical mechanisms behind the electrodynamical coupling. The footprint of Io is preceeded, downstream of Io, by a bright emission covering at least $10^{\circ}$ to $20^{\circ}$ on top of which one can at times distinguish several consecutive intensity peaks. It is not yet clear whether these peaks can be related to mutiple bouncings of Alfvén waves between the ionosphere and the Io torus, invoked to explain the Io-controlled radio decameter emissions.

Two studies have also been specifically dedicated to these radio emissions. Zarka and Queinnec (2001) demonstrated that its low frequency limit implies that the Io-controlled DAM emission must be produced on field-lines which intersect the dense plasma wake downstream of Io (and incidently that the HOM emissions originate from further out in the Io torus), whereas Queinnec and Zarka (2001) analyzed the flux, power, energy and polarization of Jovian S-bursts originating from the Io flux tube and studied their physical properties as a function of Io's longitude.

At high latitude, Pallier and Prangé (2001) have identified a very small polar cap dawnward (or westward) of the magnetic pole, in agreement with MHD models of the Jovian magnetosphere (Walker et al. 2001). At the equatorward edge of the polar cap, they have detected a variable bright auroral feature which remains fixed near magnetic noon while Jupiter rotates. They interpret it as the surface footprint of the Jovian polar cusp. 
This spot has been widely studied during the last three years. Waite et al. (2001) and Pryor et al. (2001) have highlighted its amazing variability at UV wavelengths, on time scales of a few tens of seconds, and the incredibly high peak intensity of the emission (tens of kilorayleighs), inconsistent with models of cusp precipitation on Earth. Gladstone et al. (2002) report evidence of emission of this spot in X-ray lines of highly ionized O and S ions. This implies that the charged particles have been accelerated to very high energy, by an unknown mechanism, prior to their precipitation. They also observe that the spot pulsates with a 45 min period, similar to that of radio and energetic electron bursts measured in-situ in the high latitude magnetosphere.

A number of FUV spectroscopic studies, aimed at characterizing the energy of the impinging magnetospheric particles via its penetration depth into the hydrocarbon absorbing layer have been conducted using HST and the FUV spectrographs onboard Galileo and Cassini (Ajello et al. 2001; Pryor et al. 2001; Gustin et al. 2002). Most of the time, they combine spectroscopy and imaging so that the particular auroral feature under study can now be identified. A wide range of incident particle energy is derived, depending on the auroral feature, confirming preliminary results from Prangé et al. (1998).

However, one must be careful in interpreting spectra which do not have sufficient spatial resolution, and take into account the mixing of particle populations of various origins and various characteristic energies into the same single spectrum. In order to improve the spectroscopic diagnostics, models of energy transfer between the incident particles and the atmosphere have been further developed (Dols et al. 2000, Gérard et al. 2000). A new analysis of $\mathrm{H}$ Lyman alpha spectra confirms that the $\mathrm{H}$ column abundance above the auroral source is significantly less than what could be deduced from the hydrocarbon column abundance and a standard atmospheric model (Rego et al. 2001). Interest must thus be dedicated to more elaborate models of the effect of the auroral energy input on the structure of the auroral atmosphere (Grodent et al. 2001).

Finally, Vincent et al. (2001), comparing data taken with HST in the far and mid ultraviolet, have given evidence of an influence of the auroral precipitation very deep into the stratosphere (down to $\sim 100$ mbar), possibly due to enhanced concentrations of $\mathrm{NH}_{3}$ and/or aerosols near the tropopause. Such aerosols may be assigned to the formation of aromatic compounds, and Wong et al. (2000) have developed a chemical model of aromatic compounds under energetic charged particle impact in the polar region of Jupiter.

Infrared spectroscopic studies of the Jovian auroral emissions of the $\mathrm{H}_{3}^{+}$ionospheric ion have also provided a wide range of new results over the last three years, improving both the understanding of the ion-neutral chemistry of the jovian upper atmosphere, and its dynamics and energetics, and providing a sensitive diagnostic of the ionosphere-magnetosphere coupling at Jupiter (Miller et al. 2000a,b). Achilleos et al. (2001) have applied the JIM thermospheric model, which includes coupling with the magnetosphere via energy input and cross-field-lines potential drops in the ionosphere, to the modeling of the thermospheric response to time varying magnetospheric conditions. JIM has also been used to derive for the first time auroral Pedersen conductivities, which are needed in magnetospheric models such as the Cowley and Bunce (2000)'s one, so that completely self-consistent magnetosphericionospheric-thermospheric models are now close to be available for Jupiter.

Stallard et al. (2001), generalizing a previous study by Rego et al. (1999), have derived steady-state Doppler velocities of the auroral thermosphere, using the $\mathrm{H}_{3}^{+}$ion as a tracer. They confirm the existence of a permanent auroral electrojet along the main auroral oval flowing at $\sim 1.2-1.5 \mathrm{~km} / \mathrm{s}$, in the clockwise direction as seen from the north pole. This is the first direct evidence of the large scale magnetospheric current system that models claim to be responsible for the enforced rotation of the middle magnetosphere plasma sheet. At higher latitude (maybe in the polar cap) antisunward winds are also derived suggesting again a direct coupling with the solar wind at such high latitudes. Stallard et al. (2002) have detected for the time a "hot band" line of $\mathrm{H}_{3}^{+}$in the polar ionosphere. This detection indicates that the temperature there may at times exceed the average value and reach $1250 \mathrm{~K}$, maybe up to $1500 \mathrm{~K}$. 
Far fewer studies concern the other outer planets. Trafton et al. (2000), studying the $\mathrm{H}_{2}$ quadrupole and $\mathrm{H}_{3}^{+}$IR lines from Uranus, state that auroral processes appear to play a secondary role in the total excitation.

Finally, Prangé et al. (2002) have analyzed HST FUV spectra and images of Saturn in December 2000, during the Galileo-Cassini campaign. They establish that the precipitating particles are very low energy ones, that the quiet time Kronian aurora consists of a single narrow oval, that the latitude of the emission and its brightness distribution present a clear local time asymmetry (brighter and at lower latitude in the morning sector), and that the Kronian aurora has been observed to respond strongly to a shock in the solar wind (extrapolated from Cassini measurements at the distance of Jupiter). These results anticipate very exciting findings from the Cassini mission.

\section{Titan}

\section{A. Griffith}

Research on Titan has, in the past three years, improved our knowledge of its lower atmosphere, the stratosphere (its chemistry and dynamics), the seasonal circulation in the upper atmosphere and the heterogeneity of Titan's surface. Over 80 refereed journal articles were published from January 1999 to September 2003. This work has refined our questions on Titan for the Cassini encounter in 2004 and better defined the measurements that can address these questions. Research on Titan is also being pursued within the Cassini instrument teams in order to ensure a successful mission.

The most salient features of Titan's haze, a detached layer at roughly $400 \mathrm{~km}$ and a seasonally varying difference in brightness between the northern and southern hemispheres (both detected 20 years ago by Voyager) have now been explained consistently as resulting from a pole-to-pole circulation in the stratosphere. The resulting winds carry particles to the winter pole. The summer hemisphere (thus impoverished of dark particles) appears bright compared to the northern hemisphere and a detached haze layer results (Kostiuk et al. 2001; Rannou et al. 2002).

General circulation models of Titan's atmosphere have become more sophisticated with the addition of processes inherent to a methane cycle (that is condensation, precipitation and evaporation of methane). These models however do not explain the latitudinal methane distribution and indicate that clouds preferentially occur at low latitudes, contrary to recent observations (Courtin \& Kim 2002; Gurwell \& Muhleman 2000; Kim et al. 2000; Lorenz 2001; Tokano et al. 2001).

Several groups have published maps of Titan's surface albedo at wavelengths ranging from $0.96 \mu \mathrm{m}$ to $2 \mu \mathrm{m}$. The new images of Titan confirm that Titan's surface is highly heterogeneous, and indicate further a large dynamic range in Titan's surface brightness. For example, surface albedos ranging from 0.15 to less than 0.05 , have been measured in the $\mathrm{H}$ band, averaged over $260 \mathrm{~km}$, the spatial resolution capable from ground. These groundbased observations pinpoint terrain with unique optical properties that will be targeted by Cassini (Coustenis et al. 2001; Meier et al. 2000; Roe et al. 2002).

The presence of methane condensation clouds has now been detected on a weekly basis in Titan's troposphere. Unlike terrestrial clouds, they are always observed at the same altitude (20-30 km) and are extremely sparse. The residence level of the clouds corresponds to that where convectively evolved clouds are expected, thus suggesting that Titan's high abundance of latent heat plays an active role in Titanian weather (Griffith et al. 2000; McKay et al. 2001).

Titan's chemistry continues to be investigated through laboratory simulations, theoretical work, and ground-based observations, which have led to the detection of solid organics and a derivation of the methane abundance in the upper atmosphere (Bakes et al. 2002; Balucani et al. 2000). 
Finally, ground-based measurements are studying the 29.5 year seasonal response to Titan's atmosphere to place the more time limited Cassini measurements into context.

In summary, the last triennium has witnessed tantalizing advances in our understanding of Titan's atmosphere that nonetheless continue to render Titan bewildering. Many of our major questions about Titan remain unanswered. What is the origin of evolution of Titan's atmosphere? How does Titan's organic chemistry proceed (and to what complexity)? How does Titan's methane liquid cycle differ from our hydrologic cycle? What is the nature of circulation and its main drivers in Titan's atmosphere? These questions await further ground-based studies and, moreover, Cassini's encounter with Titan in two years hence.

\section{Icy Planetary Satellites}

\section{Dale P. Cruikshank}

\subsection{Satellites of Jupiter}

Continuing studies of the icy satellites of Jupiter using the Galileo spacecraft, as well as the Cassini flyby of Jupiter in December 2000, were reported at two major meetings: "Jupiter: Planet, Satellites, and Magnetospheres," Boulder, Colorado, USA, June 2001; and "Jupiter After Galileo and Cassini," Lisbon, Portugal, June 2002. Papers from the Boulder meeting will be published in book form (Bagenal et al., 2003), and papers from the Lisbon meeting will appear in a special edition of the journal Planetary and Space Science.

Grundy et al. (1999) estimated surface temperatures of the icy satellites of Jupiter from the strength and shape of the crystalline $\mathrm{H}_{2} \mathrm{O}$ ice band at $1.65 \mu \mathrm{m}$, drawing upon laboratory work that calibrated the temperature sensitivity of this band. Black et al. (2001) extended radar backscatter studies of the icy Galilean satellites to the $70-\mathrm{cm}$ band, finding weak signals but strong polarization. The mechanisms of the unusual radar scattering properties of Europa, Ganymede, and Callisto remain unclear.

Information on the physical properties of the small satellites of Jupiter (also see above) is emerging from the Galileo spacecraft data. Simonelli et al. (2000) studied the leadingtrailing asymmetries of Thebe, Amalthea, and Metis, finding the leading side brighter than the trailing by $25-30 \%$ in all cases. They suggest that meteoroids originating outside the jovian system impact these surfaces preferentially on the leading sides, causing the brightening and ejecting the dust that forms Jupiter's ring system. Sykes et al. (2000) measured the near-infrared colors of $\mathrm{J} 6, \mathrm{~J} 7, \mathrm{~J} 8, \mathrm{J9}$, and $\mathrm{J} 11$ from detections in $\mathrm{J}, \mathrm{H}$, and $\mathrm{K}$ band images obtained in the Two-Micron All Sky Survey.

\subsection{Satellites of Saturn}

Water ice was detected in the near-infrared spectrum of Phoebe by Owen et al. (1999) and Brown (2000). Simonelli et al. (1999) derived an albedo map of Phoebe and determined the photometric properties. Owen et al. (2001) successfully modeled the spectrum of the low-albedo hemisphere of Iapetus $(0.3-4 \mu \mathrm{m})$ with a N-rich organic solid ("Triton tholin"), which has a strong absorption band at $3 \mu \mathrm{m}$, thus providing strong evidence for the presence of refractory organic material on this object. Momary et al. (2000) obtained photometry of several of the satellites in the near-infrared at the ring-plane crossing of 1995. Grundy et al. (1999) estimated temperatures of Enceladus, Tethys, Dione, Rhea, and Iapetus from the $1.65-\mu \mathrm{m}$ crystalline ice band. (For Titan, see the previous section.)

\subsection{Satellites of Uranus}

Trilling \& Brown (2000) used an infrared coronagraph to observe Miranda, Puck, Portia, and Rosalind (and Neptune's satellite Proteus) at JHK wavelengths, finding a range of colors similar to those seen in low-albedo asteroids and objects in the Kuiper disk. Grundy et al. (1999) estimated temperatures of Ariel, Umbriel, Titania, and Oberon from the 1.65- 
$\mu \mathrm{m}$ crystalline ice band. A comprehensive photometric study of 16 Uranian satellites and the rings was accomplished by Karkoschka (2001) with the HST. Bauer et al. (2002) found the $1.65 \mu \mathrm{m}$ band of crystalline $\mathrm{H}_{2} \mathrm{O}$ ice on Miranda, and evidence for an absorption at $2.22 \mu \mathrm{m}$ that may indicate the presence of ammonium hydrate.

\title{
13.4. Satellites of Neptune
}

Quirico et al. (1999) made a comprehensive study of the near-infrared spectrum of Triton, with models of all five detected volatile species, $\mathrm{N}_{2}, \mathrm{CO}, \mathrm{CO}_{2}, \mathrm{CH}_{4}$, and $\mathrm{H}_{2} \mathrm{O}$. Stringent upper limits were placed on many other volatiles, notably the hydrocarbons. Cruikshank et al. (2000) extended the work on $\mathrm{H}_{2} \mathrm{O}$, finding it impossible to determine if the ice is amorphous (favored by the low temperature) or crystalline. Forni et al. (2001) obtained spectra of Triton with the ESO New Technology Telescope, extending the spectral range and improving the signal precision over previously reported data by Quirico et al. (1999). Previously unidentified weak bands were not corroborated, and thus are probably spurious. Some enhancement of methane ice band strength may be seen in the new data.

Observational evidence for significant variations in the color and atmospheric surface pressure of Triton has begun to emerge. Buratti et al. (1999) reported major changes in Triton's reflectance in the photovisual spectral region on a time scale of months; similar changes on a longer time scale had been reported earlier. Tryka \& Bosh (1999) obtained a spectrum with the HST, finding the same reflectance as reported in Voyager data taken in 1989. Elliot et al. (2000) find a distortion in Triton's atmosphere and an overall increase in surface pressure (compared with Voyager results) from observations of a stellar occultation.

Schaefer \& Schaefer (2000) reported large-amplitude and temporally irregular variations in Nereid's brightness, while Schaefer and Tourtellotte (2001) reported an anomalously strong opposition surge from their photometric observations in 1998.

\subsection{Satellite of Pluto}

Brown \& Calvin (2000) obtained a near-infrared spectrum of Charon with the Keck telescope, and found clear evidence of the $1.65 \mu \mathrm{m}$ absorption band, showing that the surface $\mathrm{H}_{2} \mathrm{O}$ ice there is crystalline. They also found a weak absorption band suggestive of the presence of frozen ammonia or ammonium hydrate; this weak band is not uniformly distributed on Charon's surface.

\subsection{Laboratory Work}

Durham \& Stern (2001) reviewed the rheological properties of water ice in the context of the satellites of the outer planets, incorporating laboratory-derived flow laws and emphasizing the role of grain size in the flow, a factor that may be particularly important in understanding the icy outer shell of Europa. Grundy et al. (2002) reported on their laboratory measurements of the temperature-dependence of the absorption spectrum $(0.7-5 \mu \mathrm{m})$ of methane ice I. The temperature-dependent spectral features they identify offer possibilities for remote sensing determinations of $\mathrm{CH}_{4}$-ice temperatures on Triton, Pluto, and other bodies in the outer Solar System.

\author{
D. Cruikshank \\ President of the Commission \\ G. Consolmagno \\ Secretary of the Commission
}




\section{References}

Achilleos, N., Miller, S., Prangé, R., Millward, G., \& Dougherty, M. K. 2001, New J. Phys., $3,3.1$

Aharonson, O., Zuber, M. T., Rothman, D. H., Schorghofer, N., \& Whipple, K. X. 2002, Proc. Nat. Acad. Sci., 99, 780

Ajello, J. M. et al. 2001, Icarus, 152, 151

Allen, C. C., Westall, F., \& Schelble, R. T. 2001, Astrobiology, 1, 111

Anderson, J. D., Jacobson, R. A., Lau, E. L., Moore, W. B., \& Schubert, G. 2001a, J. Geophys. Res., 106, 32963

Anderson, J. D., Jacobson, R. A., McElrath, T. P., Moore, W. B., Schubert, G., \& Thomas, P. C. 2001b, Icarus, 153, 157

Bagenal, F., McKinnon, W., \& Dowling, T. (eds.) 2003, Jupiter: The Planet, Satellites and Magnetosphere, (Cambridge: Cambridge Univ. Press), in preparation

Baker, V. R. 2001, Nature, 412, 228

Bakes, E. L. O., McKay, C. P., \& Bauschlicher, C. W. 2002, Icarus, 157, 464

Balucani, N., Asvany, O., Osamura, Y., Huang, L. C. L., Lee, Y. T., \& Kaiser, R. I. 2000, Planet. Space Sci., 48, 447

Bandfield, J. L. 2002, J. Geophys. Res., 107, E6, 10.1029/2001JE001510

Bandfield, J. L., Hamilton, V. E., \& Christensen, P. R. 2000, Science, 287, 1626

Banfield, D., Conrath, B. J., Smith, M. D, . \& Wilson R. J. 2001, BAAS, 33, 1067

Bauer, J. M. et al. 2002, Icarus, 158, 178

Berman, D. C., \& Hartmann, W. K. 2002, Icarus, 159, 1

Bida, T. A., Killen, R. M., \& Morgan, T. H. 2000, Nature, 404, 159

Black, G. J., Campbell, D. B., \& Ostro, S. J. 2001, Icarus, 151, 160

Bolton, S. J. et al. 2002, Nature, 415, 987

Boynton, W. V. et al. 1999, J. Geophys. Res., 106, 17683

Boynton, W. V. et al. 2002, Science, 297, 81

Brown, M. E. 2000, AJ, 119, 977

Brown, M. E., \& Calvin, W. M. 2000, Science, 287, 107

Brown, R. et al. 2002, Lunar Planet. Sci., XXXIII, Abstract \# 2001 (CD-ROM)

Bunce, E. J., \& Cowley, S. W. H 2001a, Planet. Space Sci., 49, 261

Bunce, E. J., \& Cowley, S. W. H. 2001b, Planet. Space Sci., 49, 1089

Buratti, B. J., Hicks, M. D., and Newburn, R. L. 1999, Nature, 397, 219

Burr, D. M., Grier, J. A., McEwen, A. S., \& Kesztheyli, L. P. 2002a, Icarus, 159, 53

Burr, D. M., McEwen, A. S., \& Sakimoto, S. E. H. 2002b, Geophys. Res. Lett., 29, 10. 1029/2001GL013345

Byrne, S., \& Murray, B. C. 2002. J. Geophys. Res., 107, E6, 10.1029/2001JE001615

Cantor, B. A., James, P. B., Caplinger, M., \& Wolf, M. J. 2001, J. Geophys. Res., 106, 23653

Carlson, R. W. 1999, Science, 283, 820

Carlson, R. W. et al. 1997, Geophys. Res. Lett., 24, 2474

Carlson, R. W. et al. 1999, Science, 286, 97

Carr, M. H., \& Malin, M. C. 2000, Icarus, 146, 366

Carruba, V., Burns, J., Nicholson, P., \& Gladman, B. 2002, Icarus, 158, 434

Chapman, M. G., \& Tanaka, K. L. 2002, Icarus, 155, 324

Christensen, P. R. et al. 2000, J. Geophys. Res., 105, E4, 9623

Christensen, P. R. et al. 2001a, J. Geophys. Res., 106, E10, 23823 
Christensen, P. R., Morris, R. V., Lane, M. D., Bandfield, J. L., \& Malin, M. C. 2001b, J. Geophys. Res., 106, E10, 23873

Chyba, C. F., \& Hand, K. P. 2001, Science, 2922026

Clarke, J. T. et al. 2002, Nature, 415, 997

Cohen, B. A., Swindle, T. D., \& Kring, D. A. 2000, Science, 290, 1754

Consolmagno, G. J. 1981, Icarus, 47, 36

Cooper, B. L., Potter, A. E., Killen, R. M., \& Morgan, T. H. 2001, J. Geophys. Res., 106, 32803

Costard, F., Forget, F., Mangold, N., \& Peulvast, J. P. 2001, Science, 295, 110

Courtin, R., Kim, S. J. 2002, Planet. Space Sci., 50, 309

Coustenis, A. et al. 2001, Icarus, 154, 501

Cowley, S. W. H., Bunce, E. J. 2000, Planet. Space Sci., 49, 1067

Cruikshank, D. P. et al. 2000, Icarus, 147, 309

Dols, V., Gérard, J. C., Clarke, J. T., Gustin, J., \& Grodent, D. 2000, Icarus, 147, 251

Douté, S. et al. 2001, Icarus, 149, 107

Durham, W. B., \& Stern, L. A. 2001, Ann. Rev. Earth Planet Sci., 29, 295

Elliot, J. L. et al. 2000, Icarus, 148, 347

Feldman, W. C. et al. 2002, Science, 297, 75

Forni, O. et al. 2001, Lunar and Planetary Science XXXII, Abstract \# 1275 (CD-ROM)

Frank, L. A., \& Paterson, W. R. 2001, Trans. AGU, 82, Abstract P11A-04

Gladstone, G. R. et al. 2002, Nature, 415, 1000

Gold, R. E. et al. 2001, Planet. Space Sci., 49, 1467

Grant, J. A. 2000, Geology, 28, 223

Griffith, C. A., Hall, J. L., \& Geballe, T. R. 2000, Science, 290, 509

Grodent, D., Waite, J. H. Jr., \& Gérard, J. C. 2001, J. Geophys. Res., 106, 12933

Grundy, W. M., Buie, M. W., Stansberry, J. A., \& Spencer, J. R. 1999, Icarus, 142, 536

Grundy, W. M., Schmitt, B., \& Quirico, E. 2002, Icarus 155, 486

Gurnett, D. A. et al. 2002, Nature, 415, 985

Gurwell, M., \& Muhleman, D. O. 2000, Icarus, 145, 653

Gustin, J., Grodent, D., Gérard, J. C., \& Clarke, J. T 2002, Icarus, 157, 91

Gérard, J. C., Benot, H., Bisikalo, D. V., \& Shematovich, V. 2000, J. Geophys. Res., 105, 15795

Harmon, J. K., Perillat, P. J., \& Slade, M. A. 2001, Icarus, 149, 1

Haskin, L. A. 1998, J. Geophys. Res., 103, 1679

Head, J. W. III, Hiesinger, H., Ivanov, M. A., Kreslavsky, M. A., Pratt, S., and Thomson, B. J. 1999, Science, 286, 2134

Herd, C. D. K. et al. 2002, Geochim. Cosmochim. Acta, 66, 2025

Hoffman, N. 2000, Icarus, 146, 326

Hospodarsky, G. B. et al. 2001, in Planetary Radio Emissions V, ed. H. O. Rucker et al. (Austrian Acad. Sci. Press), 155

Hynek, B. M., Arvidson, R. E., \& Phillips, R. J. 2002, Lunar Planet. Sci., XXXIII, Abstract \#1408 (CD-ROM)

Jacobson, R. 2000, Astronom. J., 120, 2679

Jarvis, K., Vilas, F., Larson, S., \& Gaffey, M. 2000, Icarus, 145, 445

Jolliff, B. L., Gillis, J. J., Haskin, L. A., Korotev, R. L., \& Wieczorek, M. A. 2000, J. Geophys. Res., 105, 4197

Karkoschka, E. 2001, Icarus, 151, 51 
Keszthelyi, L., McEwen, A. S., \& Thordarson, T. 2000, J. Geophys. Res., 105, E6, 15027

Kieffer, S. W., Lopes-Gautier, R., McEwen, A. S., Keszthelyi, L., \& Carlson, R. 2000, Science, 288, 1204

Kim, S. J., Geballe, T. R., \& Noll, K. S. 2000, Icarus, 147, 588

Kirkland, L. E. et. al. 2002, in Instruments, Methods, and Missions for Astrobiology IV, eds. R. B. Hoover et al., SPIE Proceedings, 4495, 158

Kivelson, M. G. et al. 2000, Science, 289, 1340

Kivelson, M. G. et al. 2001, J. Geophys. Res., 106, 26121

Kivelson, M. G. et al. 2002, Icarus, 157, 507

Kivelson, M. G., Khurana, K. K., Russell, C. T., \& Walker, R. J. 2001, Trans. AGU, 82, Abstract P11A-01

Klassen, D. R., \& Bell, J. F. 2002, BAAS, 32, 1105

Knauth, L. P., \& Burt, D. M. 2002, Icarus, 158, 267

Korotev, R. L. 1999, in Workshop on New Views of the Moon II (Houston: Lunar and Planetary Institute), Abstract \#8001

Korotev, R. L. 2002, Lunar Meteorites 〈http://epsc.wustl.edu/admin/resources/moon_meteorites.html>

Kostiuk, T. et al. 2001, Geophys. Res. Let., 28, 2361

Krimigis, S. M. et al. 2002, Nature, 415, 994

Kring, D. A. 2000, GSA Today, 10, 1

Krivov, A., Wardinski, I., Spahn, F., Kruger, H., and Grün, E. 2002, Icarus, 157, 436

Ksanfomality, L. 2002, Solar System Research, 36, 267

Kurth, W. S. et al. 2001, in Planetary Radio Emissions V, ed. H. O. Rucker et al. (Austrian Acad. Sci. Press), 15

Kurth, W. S. et al. 2002, Nature, 415, 991

Lecacheux, A. et al. 2001, in Planetary Radio Emissions .V, ed. H. O. Rucker et al. (Austrian Acad. Sci. Press), 29

Liu, J., \& Richardson, M. I. 2001, Trans. A. G. U., Abstract P32E-02

Lopes-Gautier, R. et al. 1999, Icarus, 140, 243

Lopes-Gautier, R. et al. 2000, Science, 288, 1201

Lorenz, R. 2001, Geophys. Res. Let., 28, 415

Louarn, P., Mauk, B. H., Kivelson, M. G., Kurth, W. S., Roux, A., Zimmer, C., Gurnett, D. A., \& Williams, D. J.,2001 J. Geophys. Res., 106, 29883

Louarn, P., Roux, A., Perraut, S., Kurth, W. S., Gurnett, D. A. 2000, J. Geophys. Res., 105,13073

Malin, M. C., Caplinger, M. A., \& Davis, S. D. 2001, Science, 294, 2146

Malin, M. C., \& Edgett, K. S. 1999, Geophys. Res. Lett., 26, 3049

Malin, M. C., \& Edgett, K. S. 2000a, Science, 288, 2330

Malin, M. C., \& Edgett, K. S. 2000b, Science, 2901927

Malin, M. C., \& Edgett, K. S. 2001, J. Geophys. Res., 106, E10, 23429

Mallama, A., Wang, D., \& Howard, R. A. 2002, Icarus, 155, 253

Marchis, F., Prangé, R., \& Christou, J. C. 2000, Icarus, 148, 384

Mauk, B. H., Clarke, J. T., Grodent, D., Waite, J. H., Paranicas, C. P., \& Williams, D. J. 2002, Nature, 415, 1003

Max, M. D., \& Clifford, S. M. 2000, J. Geophys. Res., 105, E2, 4165

McEwen, A. S. et al. 1998a, Icarus, 135, 181

McEwen, A. S. et al. 1998b, Science, 281, 87

McEwen, A. S. et al. 2000, Science, 288, 1193 
McEwen, A. S., ed. 2001, Geology and Geophysics of Io, special section of J. Geophys. Res., 106, 32, 959

McKay, C. P., Coustenis, A., Samuelson, R. E., Lemmon, M. T., Lorenz, R. D., Cabane, M., Rannou, P., \& Drossart, P. 2001, Planet. Space Sci., 49, 79

McKinnon, W. B. et al. 2001, Geology, 29, 103

McSween, H. Y. et al. 2001, Nature, 409, 487

Meier, R., Smith, B.A., Owen, T.C., \& Terrile, R.J. 2000, Icarus, 145, 462

Mellon, M. T., \& Jakosky, B. M. 1993, J. Geophys. Res., 98, 3345

Mellon, M. T., \& Phillips, R. J. 2001, J. Geophys. Res., 106, E10, 23165

Mendillo, M. W. J., Limaye, S. S., Baumgardner, J., Sprague A., \& Wilson, J. 2001, Planet. Space Sci., 491501

Milazzo, M. P. et al. 2001, J. Geophys. Res., 106, 33121

Miller, S. et al. 2000a, Adv. Space Res., 26, 1477

Miller, S. et al. 2000b, Phil. Trans. Royal Soc. Series A, 358, 2485

Mitrofanov, I. et al. 2002, Science, 297, 78

Momary, T. W., Baines, K. H., Yanamandra-Fisher, P. A., Lebofsky, L. A., Golisch, W., \& Kaminski, C. 2000, Icarus 148, 397

Moore, J. M. et al. 2001, Icarus, 151, 93

Musselwhite, D. S., Swindle, T. D., \& Lunine, J. I. 2001, Geophys. Res. Lett., 28, 7, 1283

Mustard, J. F., Cooper, C. D., \& Rifkin, M. K. 2001, Nature, 412, 411

Nozette, S., Spudis, P. D., Robinson, M. S., Bussey, D. B. J., Lichtenberg, C., \& Bonner, R. 2001, J. Geophys. Res., 106, 23253

Owen, T. C. et al. 2001, Icarus 149, 160

Owen, T. C., Cruikshank, D. P., Dalle Ore, C. M., Geballe, T. R., Roush, T. L., \& de Bergh, C. 1999, Icarus 139, 379

Pallier, L., \& Prangé, R. 2001, Planet. Space Sci., 49, 1159

Pearl, J., Hanel, R., Kunde, V., Maguire, W., Fox, K., Gupta, S., Ponnamperuma, C., \& Raulin, F. 1979, Nature, 280, 755

Phillips, C. B. 2000, Ph. D. thesis (Tucson: Univ. of Arizona)

Pieters, C. A., Tompkins, S., Head, J. W., \& Hess, P. C. 1997, Geophys. Res. Lett., 24 1903

Potter, A. E., Killen, R. M., \& Morgan, T. H. 2002, Meteorit. Planet. Sci. 37, 1165

Prangé, R., Chagnon, G., Kivelson, M. G., Livengood, T. A., \& Kurth, W. 2001, Planet. Space Sci., 49, 405

Prangé, R., Pallier, L., Cowley, S., Bunce, E., \& Connerney, J. E. P. 2002, Magnetospheres of the Outer Planets Symposium Abstracts

Prangé, R., Rego, D., Pallier, L., Connerney, J., Zarka, P., \& Queinnec, J. 1998, J. Geophys. Res., 103, 20195

Pryor, W. R., Stewart, A. I. F., Simmons, K. E., Ajello, J. M., Tobiska, W. K., Clarke, J. T., \& Gladstone, G. R. 2001, Icarus, 151, 314

Queinnec, J., \& Zarka, P. 2001, Planet. Space Sci., 49, 365

Quirico, E. et al. 1999, Icarus, 139, 159

Rannou, P., Hourdin, F., \& McKay, C.P. 2002, Nature, 418, 853

Rego, D., Clarke, J. T., Ben Jaffel, L., Ballester, G. E., Prangé, R., \& McConnell, J. 2001, Icarus, 150, 234

Rego, D., Miller, S., Achilleos, N., Prangé, R., \& Joseph, R. D. 2000, Icarus, 147, 366

Rego, D., Achilleos, N., Stallard, T., Miller, S., Prangé, R., Dougherty, M. \& Joseph, R. D. 1999, Nature, 399, 121 
Rettig, T., Walsh, K., \& Consolmagno, G. J. 2002, Icarus, 154, 313

Rice, J. W., Parker, T. J., Russel, A. J., \& Knudsen, O. 2002, Lunar Planet. Sci., XXXIII, Abstract \# 2026 (CD-ROM)

Richardson, M. I., \& Wilson, R. J. 2002, Nature, 416, 298

Roe, H. G., de Pater, I., Macintosh, B. A. Gibbard, S. G., Max, C. E., \& McKay, C. P. 2002, Icarus, 157, 254

Ruiz, J. 2001, Nature, 412, 409

Ryder, G. 1990, Trans. Am. Geophys. Union, 71, 322

Ryder, G. 2002, J. Geophys. Res., 107, No. E4, 10.1079/2001JE001583

Santos-Costa, D., \& Bourdarie, S. 2001, Planet. Space Sci., 49, 303

Satoh, T., \& Connerney, J. E. P. 1999, Icarus, 141, 236

Schaefer, B. E., \& Schaefer, M. W. 2000, Icarus, 146, 541

Schaefer, B. E., \& Tourtellotte, S. W. 2001, Icarus, 151, 112

Schenk, P. M. 2002, Nature, 417, 419

Schenk, P. M. et al. 2001a, Nature, 410, 57

Schenk, P. M. et al. 2001b, J. Geophys. Res., 106, 33201

Sheppard, S., Jewitt, D., Fernandez, Y., \& Magnier, E. 2000, IAU Circ. \# 7525

Sheppard, S., Jewitt, D., Fernandez, Y., \& Magnier, E. 2001, IAU Circ. \# 7555

Sheppard, S., Jewitt, D., \& Kleyna, J. 2002, IAU Circ. \# 7900

Siebert, N. M., \& Kargel, J. S. 2001, Geophys. Res. Lett., 28, 5899

Simonelli, D., Kay J., Adinolfi, D., Veverka, J., Thomas, P. C., \& Helfenstein, P. 1999, Icarus, 138,249

Simonelli, D., Rossier, L., Thomas, P. C., Veverka, J., \& Burns, J. A. 2000, Icarus, 147, 353

Smith, M. D., Conrath, B. J., Pearl, J. C., \& Christensen, P. R. 2002, Icarus, 157, 259

Smith, M. D., Pearl, J. C., Conrath, B. J., \& Christensen, P. R. 2001, Geophys. Res. Let., 28,4263

Smythe, W. D., Lopes, R., Douté, S., Kieffer, S. W., Carlson, R. W., Kamp, L., \& Leader, F. E. 2001, Trans. AGU, 82, Abstract P11A-13

Solomon, S. C. et al. 2001, Planet. Space Sci., 49, 1445

Southwood, D. J., \& Kivelson, M. G. 2001, J. Geophys. Res., 106, 6123

Spencer, J. R., Jessup, K. L., McGrath, M. A., Ballester, G. E., \& Yelle, R. 2000a, Science, 288,1208

Spencer, J. R., Rathbun, J. A., Travis, L. D., Tamppari, L. K., Barnard, L., \& Martin, T. Z. 2000 b, Science, 288,1198

Sprague, A. L., Emery, J . P., Donaldson, K. L., Russell, R. W., Lynch, D. K., \& Mazuk, A. L. 2002, Meteorit. Planet. Sci., 37, 1255

Sprague, A. L., Hunten, D. M., Hill, R. E., Doose, L. R., \& Rizk, B. 2001, Icarus, 154, 1835

Stallard, T., Miller, S., Millward, G., \& Joseph, R. D. 2001, Icarus, 154, 475

Stallard, T., Miller, S., Millward, G., \& Joseph, R. D. 2002, Icarus, 156, 498

Stansberry, J. A., Spencer, J. R., Howell, R. R., Dumas, C., \& Vakil, D. 1997, Geophys. Res. Lett., 24, 2455

Sykes, M. V., Nelson, B., Cutri, R. M., Kirkpatrick, D. J., Hurt, R., \& Skrutskie, M. J. 2000 , Icarus, 143,371

Tera, F., Papanastassiou, \& Wasserburg, G. J. 1974, Earth Planet. Sci. Lett., 22, 1

Toigo, A. D., \& Richardson, M. I. 2002, J. Geophys. Res. 10.1029/2000JE001489

Trafton, L. M., Miller, S., Geballe, T. R., Tennyson, J., \& Ballester, G. E. 2000, ApJ, 524, 1059

Trilling, D. E., \& Brown, R. H. 2000, Icarus, 148, 301 
Tryka, K. A., \& Bosh, A. S. 1999, Icarus, 142, 571

Turtle, E. P. et al. 2001, J. Geophys. Res., 106, 33173

Turtle, E. P., \& Peirazzo, E. 2001, Science, 294, 1326

Vasavada, A. R., \& the Galileo SSI Team 1999, J. Geophys. Res., 104, 27133

Veeder, G. J., Matson, D. L., Johnson, T. V., Blaney, D. L., \& Goguen, J. D. 1994, J. Geophys. Res., 99, 17095

Vincent, M. et al. 2001, Icarus, 143, 189

Wadhwa, M. 2001, Science, 291, 527

Waite, J. H. et al. 2001, Nature, 410, 787

Walker, R. J., Ogino, T., \& Kivelson, M. G. 2001, Planet. Space Sci., 49, 237

Warell, J. 2002, Icarus, 156, 303

Warell, J., \& Limaye, S. S. 2001, Planet. Space Sci., 49, 1531

Wieczorek, M. A., \& Phillips, R. J. 2000, J. Geophys. Res., 105, 20417

Williams, R. M. E., Malin, M. C., \& Edgett, K. S. 2002, Lunar Planet. Sci., XXXIII, Abstract \#1807 (CD-ROM)

Wong, A. S., Anthony Y. T., Yung, Y. L., \& Ajello, J. M. 2000, ApJ, 534, L215

Wyatt, M. B., \& McSween, H. Y. 2002, Nature, 417, 263

Zarka, P., Queinnec, J., \& Crary, F. J. 2001, Planet. Space Sci., 49, 1137 